\title{
To keep biotechs trading at home, China pilots new stock market rules
}

In late March, China's stock market regulators launched a pilot program to help a select group of innovative Chinese companies offer and trade shares on the Shanghai and Shenzhen markets. This option is open to companies belonging to industries deemed strategically important to China-from internet and artificial intelligence to biotech, though most small players are still figuring out the intricacies of the pilot scheme's new rules.

So far, the rules seem better suited to luring China's tech superstars-such as Alibaba Group Holding of Hangzhou, Zhejiang; Tencent Holdings of Shenzhen, Guangdong; and JD.com of Beijing - to return to China and issue a secondary listing than to provide a means for China's burgeoning biotechs to raise capital.

The pilot has two main components. The first is to allow a select number of large Chinese companies with a market cap of $\$ 31$ billion (200 billion yuan), that have listed overseas, to issue a class of shares called Chinese Depositary Receipts (CDRs) (modeled after US American Depositary Receipts ). The second route is for innovative companies that have not listed overseas but have an operating income of $\$ 480$ million (3 billion yuan) and are valued at or over $\$ 3.18$ billion (20 billion yuan).

Although these thresholds are lower than before, for young biotechs without drugs on the market, an A-shares listing-that is, shares in renminbi currency-will remain out of reach. Service companies with strong revenues, however, such as contract research organizations (CROs) and genomics companies, stand a better chance. The entry thresholds have remained high because China's markets are dominated by retail investors, and regulators are keen to protect them from the risk associated with innovator companies.

"The (pilot's) revenue requirements are impossible for quintessential biotechs to meet unless they are a hybrid model, such as a revenue-generating contract research organization and a biotech," said Wendy Pan, partner at Sidley Austin and BayHelix board member. "In my view, the A-shares are not ready for biotech companies."

For prerevenue companies, Pan sees promise in the muchanticipated launch of the Hong Kong stock exchange's biotech chapter, expected next month. "HKEX is a more realistic approach for companies not looking to go public on the NASDAQ," says Pan.

China-based biotechs such as Hua Medicine of Hong Kong and Rockville, Maryland, Ascentage of Shanghai, Shenogen Pharma of Beijing, and JHL Biotech of Hsinchu, Taiwan, have all announced their intention to go public in Hong Kong, which is expected to go live as early as June. Meanwhile, WuXi AppTec of Shanghai, a CRO that delisted from the NYSE in 2015, was approved to list in Shanghai just days before the A-shares pilot was announced.

Three of China's leading prerevenue biotechs with new drugs in their pipelines-BeiGene of Beijing, Zai Labs of Shanghai

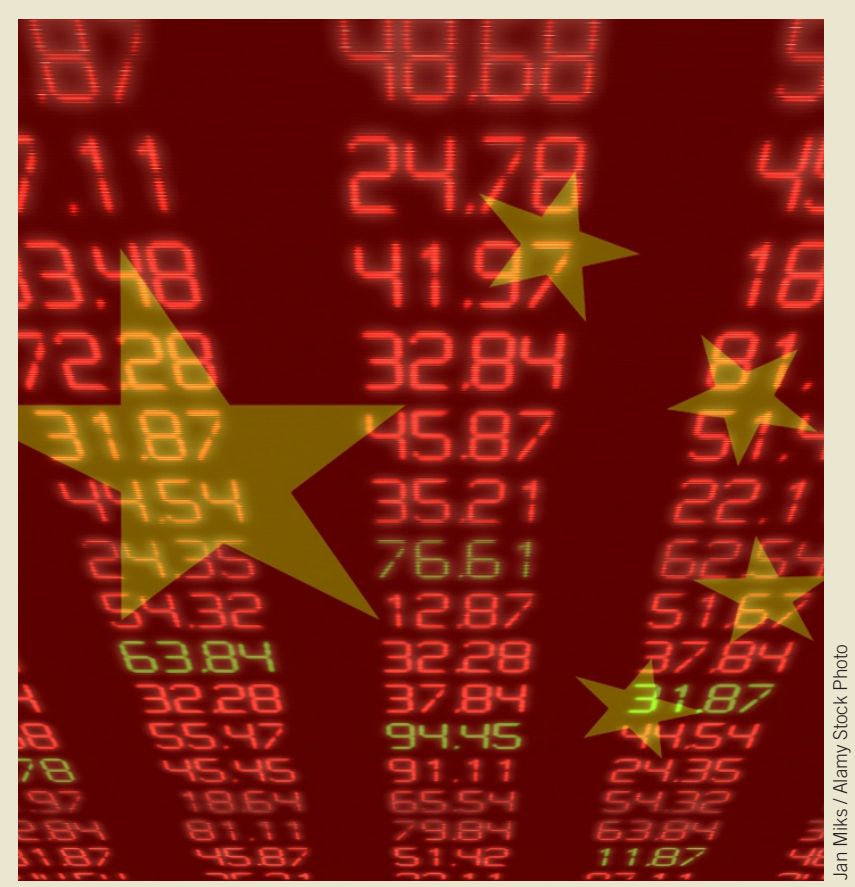

China's stock market requirements have been difficult for biotech startups to meet.

and Hutchison MediPharma of Hong Kong-are listed further afield, on the NASDAQ stock market. According to Yahoo Finance their market caps are respectively $\$ 9.09$ billion, $\$ 1.06$ billion and $\$ 3.98$ billion. Hutchison is also listed on the London Stock Exchange with a market cap of $\$ 2.77$ billion.

The pilot, soon to be launched in China, is also floating a third option for industry-leading startups to initial public offering (IPO), even prerevenue-if they have more than a \$1-billion market cap. But this criterion remains ill-defined. Industry insiders and companies are taking a wait-and-see approach to see how these rules will be rolled out. "For now we plan to closely monitor the evolution of the domestic exchanges," says Zai Labs CEO Samantha Du. Hutchison MediPharma CEO Christian Hogg agreed it is still early days to assess the pilot's impact but is encouraged by the move to open up markets in Hong Kong and on the mainland.

"The changes show an awareness by the various stock exchanges that biotech is going to be an emerging field in the region," says Hogg who predicts that local exchanges will try to satisfy the needs of biotech companies domestically rather than see them go off to foreign exchanges. "Ultimately, you have to build more than a platform, you have to build an equity capital markets ecosystem in biotech, and that will take time," says Hogg. Shannon Ellis Shanghai 